\title{
FREE DISCUSSION ON EVAPORATION
}

Dr. SChOFIELD reopened discussions on evaporation in the evening by briefly summarizing Penman's working hypotheses and invited participants to criticism.

The working hypotheses are :

1 For different crops completely covering the surface and having the same colour i.e. the same reflection coefficient for short wave radiation, the rate of transpiration is the same with the same supply of energy and if water is not limiting.

2 The rate of transpiration is determined by the weather if water is not limiting.

3 The transpiration of a short green cover is always smaller than the evaporation from an open water surface.

Comments Stanhill: What is the effect of wetting the foliage on transpiration?

Reply Penman: Wetting the leaves makes the plant behave like a water surface though one of a very peculiar shape. This will become particularly manifest if there is some stomatal control. During the night, for instance, evaporation will continue at a rate determined by energy supply and the surface exposed; whereas, if the leaves are not wetted, transpiration will be much smaller owing to closing of the stomata.

Comments Coventry : In Rhodesia when woodland is cleared and put under crops such as maize, the water level rises often to an embarrassing degree, so that the land becomes water logged in the wet season. This may indicate that maize does not evaporate at the same rate as a very sparse woodland actually a savanna. The spacing of the rows of maize is approx. $3 \mathrm{ft}$. and the plants are at most $18^{\prime \prime}$ spaced in the rows. The effect has been noted already after one or two seasons under maize.

Reply Penian : It is not an unusual experience that in replacing a vegetation that is transpiring, more or less, all the year round, by another crop that is shallower rooted and that is not on the ground all the year round, there is a rise in water level.

After some years even a small systematic difference in transpiration can result in a large difference in height of the water table.

Comments Schofield: There is further the difference in shape factor which must also be taken into account.

Comments van WiJK : VAN DuIn and Wesseling have tried to derive a relation between crop yield and water stress and found that yield depression occurs when available water is less than $0.75 E_{T}$ during the growing season which is approx. equal to 12 to $20 \mathrm{~cm}$ of water deficit.

A peculair difference was found between the years 1947 and 1949 in the Netherlands. Both were dry years. Precipitation was 65 and $64 \mathrm{~cm}$ (year) respectively and $E_{T}$ was $69 \mathrm{~cm}$ and $62 \mathrm{~cm}$ (year). Grass yields were poor in both years but 1949 was a top year for grains, potatoes, sugarbeetroots and leguminous crops whereas 1947 was a very bad year. It may be that this 
difference has something to do with the fact that water stress occurred in the first half of July in 1947 and in the second half of July in $1949{ }^{3}$ ).

Reply PenMan : One should not forget that water is not the only factor which affects yield. For sugarbeetroots 1949 was a bad year in some parts in England and 1947 was very good. This was entirely due to a severe infection with virus.

Comments vaN WIJK : Plant disease and damage by night frosts had been taken into account in the comparison referred to.

Reply Penman: We think that for early potatoes the relation holds that the wetter the soil the higher the yield is.

One can express water deficiency in two logical ways, either by stating the amount of precipitation that will restore the soil to field capacity or in terms of soil suction in an energetic scale.

Comments Slatyer: Oppenheimer and Mendel in Israël have found that with citrus trees and maize a midday depression in transpiration occurs. Our work at home shows that actual transpiration stays behind potential transpiration as calculated from weather data when a value of $7 \mathrm{~mm} /$ day is reached. The plant simply cannot follow a transpiration rate of say $10 \mathrm{~mm} /$ day.

Comments Hygen: I may draw attention to work at the agricultural college in Norway where we found a similar midday depression in both transpiration and stomatal aperture and in photo synthesis. This confirms Dr. SLaryer's observations. The question is whether the midday limitation of $7 \mathrm{~mm}$ a day is due to the inability of the water in the soil to move fast enough to the roots or in the transmission in the plant itself or in a combination of both.

Reply Penman: In my calculations I have tacitly assumed that the plant is a conducting channel for water with zero resistance which seems to be true for several species but might not be true for all kinds of plants. I have seen a behaviour as described by Dr. Slatyer in Griffith (Australia) with buckwheat that actually wilted in the middle of the day though there was plenty of water. The stomata were shut in the middle of the day.

Comments Hygen: Could Dr. Penman give more information on how the morphology of the plant comes into the picture. I think particularly of the increased ventilation in tall plants.

Reply Penman : To avoid the great complexity of trying to consider each individual leaf it is best to think in terms of available energy. Then the important area is the projected area on a horizontal plane, and the problem becomes amenable to physical treatment.

Comments Collis-George : If total energy received by an area is constant and if one crop evaporates more than another because of geometrical arrangements what happens to the excess energy which is not used in evaporation?

Reply Penman : It is hotter over a meadow than over an orchard. One has to draw up a different energy balance taking into account wind trough the trees etc.

3) VAN Duin, R. H. A., Landb.kundig Tijdschrift 66 (1954) 240. 
Comments vaN WIJK: MakKink has recently published some lysimeter measurements which show very clearly the direct relation between transpiration and available energy ${ }^{4}$ ). Transpiration is sometimes calculated using empirical formulae in which the temperature occurs instead of available energy. DE VRIES and I have made a comparison of Penman's method and Thonnthwaite's method and it appeared that transpiration when calculated by the latter method should show a phase shift as compared to the transpiration calculated according to Penman. This is due to the fact that temperature lags behind energy flux. MakKINK has actually found this shift in phase and he also found a trough in the actual transpiration curve coinciding with a trough in the radiation curve owing to clouds. There is no trough in the temperature curve.

Comments Stanhild: Could the method still be used in cases when a physiological control takes place as e.g. under arid conditions or is the physical approach restricted to transpiration which is equal to potential evapotranspiration or perhaps less that owing to limiting soil moisture which is not a physiological factor?

Reply Penman : I have sufficient faith in the method to believe that it applies over a wide range of climatic conditions and that it might be modified so as to deal with arid conditions. I fully appreciate, however, the difficulties involved in doing so.

Comments SMrru : We have used the method to calculate irrigation needs in several parts of Great Britain and for crops as unalike as grass and hops. It was found that the results were entirely satisfactory for practical purposes. No difference in transpiration between the crops was assumed. The yields obtained were perhaps not the maximum possible yields but the method worked under field conditions. I suggest that we should in practice avoid wasting our time considering small differences. For example, we should avoid adding the extra half-inch of irrigation water which theoretically would give us an increased yield, for if the irrigation is followed by a period of rain then the crop may suffer from an excess of water. This has happened during experiments and demonstrations.

Mr. SMITH giving a summary, said :

1 Daily (or other) averages do not appear to be very misleading when dealing with approximate answers over periods of ca 5-10 day minimum. For precise truth they are obviously insufficient over small periods.

2 We need to know

a departure of actual transpiration from potential.

b departure of growth from maximum, not necessarily the same as (a).

c economic problem whether it will pay a farmer to maintain full growth.

Comments Staple: Dr. Wilcox at Summerland B.C. had found that the growth and development of fruit trees is reduced when the available soil moisture is exhausted in any part of the zone occupied by the tree roots. Irrigation of fruit trees is advisable when the top layer of soil is reduced to the wilting point. On growing cereals, of course, it is known that the volume or

4) MаккıNк, G. F., Landb.kundig Tijdschrift 67 (1955) 267. 
depth occupied by roots increases continuously throughout the growing season, and this must influence the effective root tension or total available moisture.

Comments DeY : DeY gave a survey of the results obtained with the lysimeters at Castricum. The primary aim is to find out whether the afforestation in the dunes will be profitable for the winning of potable water. There are 4 lysimeters; one has a bare sand surface, the second is covered by a low vegetation, the third contains deciduous trees, the fourth needle leaved trees. Meteorological data, wind velocity, precipitation, soil and air temperature, hours of sunshine, evaporation from pans are measured. Soil moisture is now measured by gypsum blocks. Only figures of yearly evaporation are at present available. They are given in the following table.

Tabel 1. Evaporation and transpiration in the lysimeters at Castricum. The evaporation from the sand surface is taken as a reference for comparison.

\begin{tabular}{|c|c|c|c|c|c|c|c|}
\hline \multirow{2}{*}{ Year } & \multirow{2}{*}{$\begin{array}{c}\text { precip. } \\
\text { mm }\end{array}$} & \multicolumn{6}{|c|}{ Evaporation and transpiration $(\mathrm{mm})$} \\
\hline & & \multicolumn{2}{|c|}{ sand } & low veg. & deciduous & \multicolumn{2}{|c|}{ coniferous } \\
\hline 1948 & 637 & 158 & & 342 & 304 & \multicolumn{2}{|c|}{376} \\
\hline & & & \multicolumn{4}{|c|}{ Evaporation and transpiration relative to sand } & P.E. \\
\hline $\begin{array}{l}1948 \\
1949 \\
1950 \\
1951 \\
1952 \\
1953\end{array}$ & $\begin{array}{r}637 \\
748 \\
1042 \\
995 \\
930 \\
639\end{array}$ & $\begin{array}{l}158 \\
203 \\
252 \\
217 \\
182 \\
155\end{array}$ & $\begin{array}{l}1 \\
1 \\
1 \\
1 \\
1 \\
1\end{array}$ & $\begin{array}{l}2.16 \\
2.24 \\
2.10 \\
2.28 \\
2.51 \\
2.66\end{array}$ & $\begin{array}{l}1.91 \\
2.00 \\
2.00 \\
2.18 \\
2.35 \\
2.48\end{array}$ & $\begin{array}{l}2.38 \\
2.66 \\
2.50 \\
2.67 \\
3.38 \\
3.12\end{array}$ & $\begin{array}{l}649 \\
628 \\
622 \\
583 \\
616 \\
587\end{array}$ \\
\hline
\end{tabular}

The average precipitation for the 12 year period 1942-1953 was $816 \mathrm{~mm} /$ year. The average evaporation from bare sand amounted to $196 \mathrm{~mm} /$ year. The size of the lysimeters is $25 \times 25$ meters and a watertable is maintained at 2.25 meters below surface. The bare soil is protected against wind erosion by dead wood. Potential evapotranspiration has been calculated with Pexman's method; it applies to a water surface. The meteorological data were obtained at the Lysimeter station.

Comments Penman: He draws attention to the difference between the coniferous vegetation which goes on transpiring in winter and the low vegetation and deciduous trees which do not.

Comments de Vries and Schofield : They observe that it is better to use transpiration of the coniferous trees as a reference level since it approximates most nearly potential evapotranspiration over a year.

Evaporation from sand exaggerates the differences and besides it depends highly upon rainfall distribution. 